\title{
The French Emigrés in Europe and the struggle against Revolution, 1789-1814
}

Jean-Paul Bertaud

\section{(2) OpenEdition \\ 12 Journals}

Édition électronique

URL : https://journals.openedition.org/ahrf/1054

DOI : 10.4000/ahrf.1054

ISSN : 1952-403X

Éditeur :

Armand Colin, Société des études robespierristes

\section{Édition imprimée}

Date de publication : 1 mars 2001

Pagination : 135-136

ISSN : 0003-4436

\section{Référence électronique}

Jean-Paul Bertaud, «The French Emigrés in Europe and the struggle against Revolution, 1789-1814 », Annales historiques de la Révolution française [En ligne], 323 I janvier-mars 2001, mis en ligne le 21 avri 2004, consulté le 24 avril 2022. URL : http://journals.openedition.org/ahrf/1054 ; DOI : https://doi.org/ 10.4000/ahrf.1054

Ce document a été généré automatiquement le 24 avril 2022.

Tous droits réservés 


\title{
The French Emigrés in Europe and the struggle against Revolution, 1789-1814
}

\author{
Jean-Paul Bertaud
}

\section{RÉFÉRENCE}

The French Emigrés in Europe and the struggle against Revolution, 1789-1814, edited by Kirsty Carpenter and Philip Mansel, London, Macmillan Press, 1999, 236p. index.

1 L'ouvrage rassemble les contributions présentées au colloque de 1997 portant sur «Les émigrés français en Europe de 1789 à 1814». Après deux études, sur l'organisation politique (P. Mansel) et militaire (F. d'Agay), l'ouvrage nous conduit sur les chemins des émigrés à Londres (K. Carpenter), en Hongrie (F. Toth), au Portugal (D.Higgs), en Prusse (T. Höpel), à Édimbourg (Mackenzie-Stuart) et aux États-Unis (T.Sonowski). Cinq communications traitent des thèmes de la religion et de la culture dans les milieux de l'émigration: le roman (L.Crook), l'artiste Danloux (A.Gooden), la République vue à travers la presse des émigrés à Londres (S. Burrows), Burke, Boisgelin et les politiques des évêques émigrés (N. Aston), enfin le clergé français émigré en Grande-Bretagne (D.A. Bellenger).

2 Nous connaissions déjà les difficultés éprouvées par le gouvernement en exil et par l'armée des princes, les communications les remettent en perspective et permettent de juger de l'état de dépendance -pour ne pas dire de servilité- dans laquelle les émigrés se trouvèrent pour l'organisation et l'utilisation de leurs forces. L'ouvrage a surtout le mérite de nous faire vivre au quotidien l'adaptation des émigrés aux différents pays de l'ancien et du nouveau continent où quelques-uns firent souche. S'ils n'oublièrent pas le passé, tous ne furent pas «de ces hommes dont la patrie ne connût en 1815 que les prétentions et qui exigèrent d'elle le prix des services rendus à l'étranger». Quelques-uns tirèrent enseignement de leurs périples et prirent leur distance avec les 
tenants d'une Restauration pure et simple de l'Ancien Régime. Partout -et à leur corps défendant- ils apportèrent la parole de la Révolution. Leur vie nouvelle s'accompagna de déchirements profonds qu'à travers des cas individuels les auteurs nous font toucher $\mathrm{du}$ doigt et dont ils nous montrent les résonances dans le domaine artistique et littéraire. Le romantisme y trouva quelques-unes de ses racines. 